\title{
Economía y juego en Celestina
}

\section{Enric Mallorquí-Ruscalleda}

Published online: 27 May 2010

(c) Springer Science+Business Media B.V. 2010

Abstract In this work, I explore the "deep structure" inherent in the text of Celestina. By "deep structure" I mean a playful structure with which we can systemize the relationships that occur between the characters and their decisionmaking, especially between Celestina and Calisto. My approach to this thesis is interdisciplinary; more specifically, I apply the critical claims offered by modern game theory and sociology, with the intention of bringing to light an aspect of the work which has been up to now largely disregarded by Celestina critics: the role of games. This analysis is accomplished while keeping in mind the political, sociocultural and economic background of the times in which the text is situated.

Keywords Celestina $\cdot$ Symbolic economy - Interdisciplinarity .

Game $\cdot$ Mercantilism $\cdot$ Precapitalism $\cdot$ Game theory

Versiones preliminares de este artículo fueron presentadas, respectivamente, en el 40 Congreso de la Asociación Canadiense de Hispanistas (2004) y en el 59 Annual Kentucky Foreign Language Conference (2006). Por ello, no quiero dejar pasar esta oportunidad para mostrar mi más sincero agradecimiento tanto a los asistentes como a los miembros organizadores de las sesiones de los mencionados congresos, Enrique Fernández y Aníbal A. Biglieri, respectivamente, la oportunidad que me brindaron.

E. Mallorquí-Ruscalleda (四)

Department of Spanish \& Portuguese Languages \& Cultures, Princeton University,

359 East Pyne Bldg., Princeton, NJ 08544, USA

e-mail: emallorq@princeton.edu 
literario ${ }^{4}$ y que aquí sirve para pensar esta nueva dimensión lúdica, y lo que ella implica-como, por ejemplo, en la configuración de los personajes, en sus acciones y en sus interrelaciones-de Celestina. Pero no sólo esto, ya que, como se advertirá, una aproximación de este tipo permitirá demostrar formalmente cómo Calisto, con su actitud, no se adscribe al sistema de valores del amor cortés. Al respecto vale la pena señalar que se considerarán aquí a los personajes cómo si de carne y hueso se trataran. Soy plenamente consciente de los problemas que ello puede ofrecer a algunos lectores, de buen seguro los mismos que seguramente se opondrían a una lectura del texto desde una perspectiva psicoanalítica $-\mathrm{y}$ que ha ayudado a iluminar un sinfín de textos de todas las épocas y tradiciones-, y, por lo contrario, abogarían a favor de la intención autorial, aspecto, por cierto, no faltado de controversia. Por ello no pretendo hacer aquí apología de un método, sino de apuntar cómo ciertas disciplinas o métodos hasta ahora bandeados por una gran parte de la crítica literaria-en parte por una cerrazón intelectual que limita el texto a nuevas lecturas, hecho que justifican al otorgar un supuesto anacronismo al acto de pensar ciertos problemas medievales y de la modernidad temprana a partir de teorías contemporáneas, considerando a sí más que a la ligera los aportes de la hermenéutica contemporánea-pueden ser de gran utilidad para iluminar ciertos aspectos de algunos textos literarios hispánicos, como el que aquí me ocupa; en otras palabras, de lo que se trata es de abrir su sentido, hermenéuticamente hablando. Bajo ningún realidad, permitió enriquecer el discurso de otras disciplinas" (Martínez 84) se considera necesario aquí hacer uso de un discurso interdisciplinar, en el que la teoría de juegos, con las matemáticas como parte esencial, y la sociología tendrán un papel fundamental, para abrir el texto de Rojas a nuevas lecturas/interpretaciones centradas en el juego, que tanta importancia tuvo en la época, como muy bien nos enseñó Huizinga en su clásico Homo ludens.

Con todo, cabe advertir que, ni de lejos, todo lo que aquí se dirá pretende ser nuevo o novedoso, ya que una marcada influencia maravalliana se deja notar aquí y allí. Lo que se persigue con este ensayo es, concretamente, demostrar el potencial que una herramienta teórica como la teoría de juegos ${ }^{3}$ puede aportar al estudio

\footnotetext{
' La enumeración sería muy larga. Baste, como ejemplo, Emilio de Miguel Martínez, La Celestina de Rojas (Madrid: Gredos. 1996) 302-3.

${ }^{2}$ Me referiré a Fernando de Rojas de forma totalmente arbitraria para identificar al autor, o autores, de Celestina, a pesar de que, en mi opinión, en la obra hay un autor colectivo o múltiple, utilizando la terminología propuesta por Gilles Deleuze y Félix Guattari en Mille plateaux (París: Minuit, 1980), que responde a la mentalidad de la época. Además, este autor colectivo muy probablemente se materializa en la intervención de un grupo de autores, que, a su vez, construirían la obra como un juego. Entre estos autores podríamos contar con Rojas y Luis de Lucena, autor por esa misma época de la Repetición de amores e arte de axedrez: con CL juegos de partido (h. 1497), casi con toda seguridad intertexto de
Celestina.

${ }^{3}$ La teoría de juegos es el marco teórico fundamental para el estudio de problemas de decisión multipersonales y de intercambio y de negociación económica, aunque aqui se interpretará y traducirá al multipersonales y de intercambio y de negociación económica, aunque ąur se interpretará y traducirá al lenguaje común. Dicho de otro modo, la teoria de juegos es en "cónticos de los juegos formales" (Cañas 269) y como el "conjunto de estudios en economía, sociología, política, psicología... que pretende por una parte describir y por otra dar directrices normativas de la racionalidad estratégica en la conducta humana. Para conseguir estos propósitos se modelizan las situaciones sociales como juegos formales, y se interpretan los resultados obtenidos en la teoría de juegos [véase arriba, la primera acepción] sobre juegos formales como directrices de conducta racional para esas situaciones sociales" (Cañas 270).
}

De hecho, que se haya podido documentar, sólo existen algunos trabajos que desde este marco teórico abordan la conocida novela de Jorge Volpi titulada En busca de Klingsor. A un nivel más general, la teoría de juegos, aunque se haya utilizado de forma casi nula en el terreno del análisis literario de los textos hispánicos, cuenta con cierta tradición en el estudio de otras tradiciones nacionales -especialmente la francesa y la norteamericana- y comparadas. Para un estado de la cuestión de las aplicaciones de la teoría de juegos al estudio de la literatura véase el trabajo de Steven J. Brams, "Game Theory and Literature," Games and Economic Behavior 6.1 (1994): 32-54. Aunque publicado hace ya bastantes años, lo cierto es que Brams resume muy bien las líneas principales de investigación que se han continuado siguiendo hasta la actualidad, a pesar de que, comn afirmar Marie-Laure Ryan, "la dificultad de la aplicación de las nociones de a per y perder a la literatura explica por que el campo matemático de la teoría de juegos y la seḿn córica del juego de Jaco Hinikka tienen poco impacto en la le la teoría de jus , via de acercamien," al Literature," Canadian Review of Comparative Literafure/Revue Canadienne de Littérature Comparée 12 (1985). En el campo de la literatura española medieval y de la modernidad temprana, la teoría de juegos nos proporciona las herramientas teóricas necesarias para abordar, por ejemplo, el estudio de los intercambios económicos y las negociaciones y estrategias que se llevan a cabo en el Cantar de mio Cid. Igualmente válidas serian las aproximaciones que desde este punto de vista nos permitiría acercarnos al estudio de las negociaciones del sujeto colonial o, por ejemplo, al análisis del papel de las emociones y/o de la racionalidad de las decisiones por diferentes personajes conducen a un final trágico, o bien las implicaciones éticas del juego y su relación con el nacimiento de la moderna subjetividad o en el estudio de los cuerpos de conocimiento y cómo estos se manejan. En este sentido podrian leerse las sucesivas hijas de Celestina que, a diferencia de ella no mueren durante el juego ya que, precisamente, es a partir de la mejor estión del cuerpo de conocimiento dejado por Celestina que saben manejarse de mejortir de en el arte de jugar. Por todo ello me atrevo a decir que las posibilidades algunos de los principales problemas que nuestras letras plantean son prácticamente ilimitadas. Aquí tan sólo se han enumerado algunas. Sin embargo, quizás, con respecto a Celestina, una de las magníficas posibilidades que el método ofrece es hacerlo más atractivo y adecuado, si es que alguna falta le hace, para su enseñanza a las nuevas generaciones de estudiantes y lectores, tan acostumbrados a vivir con los juegos y de las realidades virtuales que las nuevas tecnologías nos ofrecen de la lectura de Celestina. 
concepto se presenta este análisis como una verdad inmanente, sino como la primera tentativa de ensayo de un nuevo modelo de pensamiento.

Celestina, ya se advierte ya desde el mismo prólogo, viene determinada a través del concepto de amor como contienda: "[t]odas las cosas ser criadas a manera de contienda..." Para ello retoma las palabras de Heráclito, a quien cita. Este proceso de citación intertextual debe entenderse como una explicación de la trama, "en la que todos sus personajes, desde los más nobles hasta lo más plebeyos, experimentan la vida como un campo de batalla en el que deben luchar por sus propios intereses" (Morros, "Introducción" ix).

La metáfora de la "contienda/la vida como un campo de batalla," se puede pensar en relación con la alusión a las justas de amor a las que se alude en el tercer auto:

Coxquillosicas son todas, mas después que una vez consienten la silla en el envés del lomo, nunca querrían holgar: por ellas queda el campo: muertas sí, cansadas no. (III, 102-3)

Si así se considera, ello remite al mundo caballeresco y a sus tomeos de carácter lúdico, lo que puede relacionare con la categoría antropológica de agoncompetición-y con una conceptualización del juego como la que sigue y que tomo como definición de trabajo inicial:

[e]l juego, en su aspecto formal, es una acción libre ejecutada 'como si' y sentida como situada fuera de la vida corriente, pero que, a pesar de todo, puede absorber por completo a un jugador, sin que haya en ella ningún interés material ni se obtenga en ella placer alguno, que se ejecuta dentro de un determinado tiempo y un determinado espacio, que se desarrolla en un orden sometido a reglas. (Huizinga 27)

De esta definición de "juego" interesa destacar varios aspectos, los cuales están estrechamente relacionados tanto con el modelo teórico como con los objetivos que se persiguen aquí. Uno de ellos es el del 'como si' con el cual Huizinga se refiere al juego en tanto que escape de la realidad, esto es, como un mundo virtual y posible. El mundo del juego viene construido a imagen de la realidad aunque con la particularidad de que este simulacro virtual permite usar el pasado en un presente de caras a ensayar futuribles comportamientos individuales y sociales, políticos y económicos. Por tanto, en el juego uno se enfrenta a un mundo donde lo virtual debe interpretarse como potencialidad verosímil, o veraz, capaz de convertirse en real. ${ }^{6}$

\footnotetext{
5 Se ha escrito bastante sobre el tema del conflicto en Celestina. Por ejemplo: Consolación Baranda, La Celestina y el mundo como conflicto (Salamanca: Ediciones Universidad de Salamanca, 2004) o, enfocándose en las imágenes de aves de rapiña y su presa, Laura Vivanco, "Birds of a Feather: Predator and Prey in Celestina." Celestinesca 26.1-2 (2002): 5-27, además de Joaquín Gimeno Casalduero, "La Celestina y su prólogo," Actas del X Congreso de la Asociación Internacional de Hispanistas, Vol. I, Ed. Antonio Vilanova (Barcelona: PPU, 1992) 215-222. Sería prolijo aportar más ejemplos.

${ }^{6}$ En este sentido cabe resaltar la necesidad de escribir estudios sobre Celestina orientados al análisis de la presencia y el uso del modo verbal subjuntivo, así como de la primera y persona del singular en la obra, ya que, en conjunto, se constituyen como los recursos más importantes para la construcción ficcional de
} estas virtualidades-para una explicación detallada de estos conceptos, véase Marie-Laure Ryan, La
A pesar de la utilidad de la definición de Huizinga, cabe mencionar que ésta presenta una considerable limitación al afirmar que el juego no persigue ni presenta "ningún interés material" ni se obtiene a partir de ningún provecho. Con ello, Huizinga no contempla los juegos que pueden venir condicionados por cuestiones materiales, ${ }^{7}$ como los que aquí se estudian. ${ }^{8}$

Más concretamente, en el texto de la Tragicomedia se dan cuatro juegos: (a) el que establece Melibea per se como estructurador de su identidad; (b) el juego entre Celestina y Calisto; (c) el juego entre Celestina y los criados, Pármeno y Sempronio y, (d) el que establecen, entre sí, Pármeno y Sempronio. ${ }^{9}$ Aunque todos estos juegos se desarrollan de forma simultánea en buena parte de la obra, e incluso, uno origina o es simplemente corolario del otro, a continuación se va a dedicar atención preferente al juego entre Celestina y Calisto, en quienes se personifican dos tipos de personas muy características de la temprana modernidad. Más específicamente, Celestina encarna la característica del homo economicus, ${ }^{10}$ esto es, la del "individuo racional implacablemente dedicado a maximizar sus propias ganancias" (Cañas 266). Y Calisto representa un cruce entre el homo economicus y el homo emoticus, " mucho más cercano a la naturaleza de las personas reales, caracterizadas por ser "un complicado híbrido de especies que puede ser gobernado tanto por la emoción como por la fría lógica y el egoísmo" (Cañas 266). Estos dos agentes negocian, ${ }^{12}$ por una parte, con el cuerpo de Melibea, en tanto que objeto puramente sexual, entendido como capital simbólico, ${ }^{13}$ con la intención de sanar el dolor de Calisto; y, por otra parte, intercambian una serie de bienes materiales que recaerán en posesión de

\section{Footnote 6 continued}

narración como realidad virual: la inmersión y la interactividad en la literatura y en los medios electrónicos (Barcelona: Paidós, 2004), esp. las páginas 43 a 69.

A pesar de la fortuna que el concepto de Gadamer de juego expuesto en su Verdad y método (Salamanca: Sígueme, 1997, esp. pp. 143 ss.) y La actualidad de lo bello (Barcelona. Paidós, 1998, esp. pp. 66 ss.), en tanto que categoría-junto con el símbolo y la fiesta-para definir lo más característico de la experiencia estética, no cabe obviar aquí sus limitaciones por lo que a mis propósitos se refiere. Me refiero, concretamente, a la cuestión del sujeto del juego, al objetivo del juego, así como a la defensa del primado del juego frente a la conciencia del jugador que, en su propuesta, el filósofo alemán desarrolla primado der ju hay espacio aqui para ahondar en las diferencias teóricas que se estaber la teoría de juegos y el de Gadamer.

${ }^{8}$ Los estudios críticos tocantes a los aspectos lúdicos de Celestina son casi nulos, a excepción del trabajo de Carlos Rubio de la Llave titulado "El juego de seducciones en La Celestina: una estructura dramática." En su estudio, Rubio de la Llave presenta un exhaustivo y detallado análisis del esquema del juego de seducciones-- en el que cada personaje desarrolla los papeles de seductor y seducido-y muertes que aparecen en el texto primitivo de la Comedia en dieciséis actos Su análisis muestra como la "obra pctá disper en ide, contextualiza y engloba el texto.

9 Al respecto tengo preparada una monografía que espero poder someter a revisión muy pronto.

${ }^{10} \mathrm{Al}$ que también se puede denominar "Yo egoísta."

11 "[I]ndividuo que se rige por las emociones" (Cañas 266).

12 A lo largo de este trabajo me referiré indistintamente a jugador y agente.

${ }^{13}$ Sigo para ello a Pierre Bourdieu, Razones prácticas. Sobre la teoría de la acción (Barcelona: Anagrama, 1997). 
Celestina una ve $\%$ que haya llevado a cabo una variedad de transacciones que tienen como vehículo principal el discurso erótico. ${ }^{14}$

En una época como la que se inserta el texto, protagonizado por los numerosos y profundos cambios sociales, el tema dinero es visto como verdadero motor del mundo: "Bulla moneda y dure el pleito lo que durare. Todo lo puede el dinero" (III, 102). Baste para ello sólo recordar que el creciente y explosivo desarrollo de la economía mercantilista de la época se vio favorecido por el surgimiento de las sociedades urbanas en las que, en poco tiempo, se sustituiría el tradicionalismo económico medieval por el incipiente capitalismo. Quizás fuera ésta una de la razones por las que Rojas decidió ambientar y situar su obra en una ciudad, que, a pesar de representar un 'microcosmos' social y urbano, permite extrapolar las relaciones que en ella se establecen, pero, sobre todo, muestra el paradigma del funcionamiento de la incipiente modernidad.

Es en esta ciudad en la que Rojas organiza y desarrolla toda esta serie de juegos articulados a partir de las complejas interacciones entre el amor carnal y la economía. En este sentido que se ha afirmado que "la sexualidad constituye, en efecto, la base de la actividad económica de esta ciudad en miniatura" (Deyermond 4). Dado que todo juego debe enmarcarse espacial y temporalmente, esta ciudad, paradigmática y prototípica, configura lo que Huizinga ha denominado como arena, círculo mágico, templo, pantalla y corte de justicia; es decir, el espacio, en tanto que campo de juego, en el que se ponen en práctica reglas específicas (35-6) y en el que se ponen a prueba las habilidades y maestrías de los jugadores.

En el caso de Celestina, la ciudad es un espacio virtual que no debe ser identificado con ninguna ciudad específica. ${ }^{\text {is }}$ En la obra del bachiller, lo que importa del espacio urbano es que funciona como elemento contextualizador del juego. La ciudad es el escenario donde se representa el juego mercantil del mundo renacentista que es, principalmente, urbano. La ciudad es un espacio de movilidad referencial, lo que conlleva la posibilidad de desplazarse por el tiempo y el espacio del texto. Ésta permite, entonces, trazar un itinerario preciso de las acciones de los personajes, ya que ésta es presentada a través de todos los juegos que se dan en Celestina. Por ello debe ser considerada como una ciudad prototipo que permite que el oyente o el lector pueda apropiársela gracias a la familiaridad con cualquier otro espacio que pudiera existir en la época. A partir de lo anterior se aclara que lo importante para este trabajo es reconocer y pensar en que la idea de que la ciudad que Rojas representa es una urbe caracterizada por su necesidad y deseo continuado del juego, como requisito para explicar simbólicamente el mundo de finales del siglo XV.

Concretamente, el juego entre Celestina y Calisto es una competición bipersonal finita que se inicia en el momento de la negociación del 'dolor' que ha dejado el

${ }_{14}^{14}$ Véanse al respecto, por ejemplo, los trabajos de Alan Deyermond: "Hilado-Cordón-Cadena: Symbolic Equivalence in La Celestina,"Celestinesca, 1.1 (1977): 6-12 y, su continuación, "Symbolic Equivalence in La Celestina: A Postscript," Celestinesca, 2.1 (1978): 25-30.

15 Véase la acertada argumentación que Miguel Ángel Ladero Quesada, "Aristócratas y marginales: aspectos de la sociedad castellana de Celestina," Estudios sobre Celestina, ed. Santiago López Ríos (Madrid: Istmo, 2001) 213-40, que, de alguna forma, confirma, o apoya, esta lectura rechazo de Melibea en el joven. ${ }^{16}$ Este juego parte de la negociación por el disfrute del cuerpo de la doncella, en tanto que objeto sexual capaz de 'sanar' el malestar o carencia de los jugadores. Pero, sobre todo, su cuerpo constituye el capital simbólico necesario para intercambiar y movilizar los bienes de la sociedad. Por este motivo, a partir de las estrategias que utilizan los jugadores involucrados, la forma óptima de estudiar estas transacciones es a través de la teoría de juegos, ya que pretende "conseguir una auténtica comprensión del problema del intercambio, estudiándolo desde un enfoque completamente diferente; es decir, desde la perspectiva de un juego de estrategias" (Davis 15).

Este juego, que consta de varias jugadas, lo inicia Celestina, de acuerdo con un comportamiento bayesiano-racional, ${ }^{17}$ quien asigna una probabilidad ${ }^{18}$ subjetiva a cada una de las alternativas posibles, y con una estrategia dominante y ganadora, ${ }^{19}$ que cuenta con la colaboración de Sempronio. Desde un primer momento se trata de un juego cooperativo con información perfecta, puesto que ambos jugadores poseen un conocimiento común del juego. Gracias a Sempronio, Calisto se pone en contacto con la medianera, sabiendo de antemano que ella "promoverá y provocará a lujuria, si quiere" (I, 47). Por esta misma razón, ambos jugadores conocen las estrategias del juego y las acciones que ha de emprender cada agente en cada contingencia posible del juego, así como los intereses del otro jugador. Pero, sobre todo, Calisto y Celestina saben que, para maximizar el resultado, la mejor estrategia es la cooperación. De hecho, las opciones que se le ofrecían a Calisto en este juego no le daban otra alternativa. Calisto, al no decidir comportarse con las reglas del amor cortés, ${ }^{20}$ debe cooperar con Celestina, ya que ella le ofrece el remedio para sanar su dolor a través de la obtención de su premio: el cuerpo de Melibea. Sin embargo, dicha cooperación le repercutirá económicamente, dado que las acciones de Celestina están siempre condicionadas a los diferentes premios, o pagos, esto es, bienes materiales, que Calisto le puede proporcionar.

${ }_{16}$ Me refiero a la enfermedad de amor que según la medicina árube medieval que nos trangicó Avicena en su Al-Qanum fi al-tibb o Canon de la Medicina por un error de la virtus aestimativa. La bibliografía al respecto es abundante. Sirvan, como ejemplo, los trabajos de Bienvenido Morros, "La difusión de un diagnóstico de amor desde la Antigüedad hasta la época moderna," Boletín de la Real Academia Española 79.276 (1999) 94-150 y de Marcelino V. Amasuno Sarraga, "Hacia un contexto médico para Celestina:" Sobre "amor hereos" y su terapia, Celestinesca 24.1-2 (2000a): 135-69 y "Calisto, entre "amor hereos' y una terapia falaz," Dicenda: Cuadernos de filologia hispánica 18 (2000b): 11-49. Por la riquísima documentación que aporta es igualmente interesante el libro de Guillermo Serés transformacion de los antantes: imagenes del anor de la Antigüedud al Siglo de Oro (Barcelona: Critica transfon ginas $16-23$.

17 Entendido como la actitud con la que un jugador asigna una probabilidad subjetiva a cada una de las alternativas posibles del juego.

${ }^{18}$ Se entiende por probabilidad "[u]n número entre 0 y 1 que el decisor asigna a cada suceso incierto incluido en un modelo. Ese número pretende reflejar, a través de una asignación primitiva o derivada, la esperanza que tiene en que ocurra finalmente el suceso" (Cañas 268).

${ }^{19}$ Se considera estrategia dominante "una estrategia (en un conjunto de decisiones sucesivas) (que] domina a otra cuando, sean cuales sean los sucesos inciertos que se den, la utilidad de sus resultados es mayor que la utilidad de los resultados de la acción dominada. Una opción o estrategia es dominante si domina a todas las demás opciones del modelo" (Cañas 263).

${ }^{20}$ Sería muy iluminador escribir un estudio de la transformación de las reglas del amor cortés desde la teoría de juegos, ya que aportaría datos muy reveladores sobre su periodización. 

decidiera no cooperar con Celestina, el joven conservaría toda su riqueza y, a la vez, se mantendría fiel al código moral de la burguesía ascendente del momento. Sin embargo, optar por esta vía le impediría sofocar su dolor con Melibea.

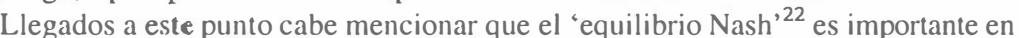
este juego porque corresponde a una situación en que dos partes rivales están de acuerdo con dete rminada situación de juego, por lo que cualquier alteración de los términos de la ne gociación ofrece desventajas a ambas partes. De esta forma, ambos jugadores van a maximizar sus resultados y, así, cada uno de ellos obtendrá su tan anhelado y codiciado premio. En este sentido, el juego de suma no-cero es ideal para estos dos personajes, ya que su antagonismo como jugadores se asienta, como diría María Rosa Lida, "sobre una semejanza básica: ambos dan rienda suelta a su particular apetito, desentendiéndose de su prójimo como no sea para usarle de instrumento" (506).

Por su parte, Celestina, también cuenta, a priori, con dos posibles estrategias a seguir. La primena consiste en ayudar a Calisto a conquistar a Melibea y así curarle su mal de amor: A cambio, Celestina conseguiría una importante recompensa económica-las cien monedas de oro, el manto. Su otra opción ${ }^{2.3}$ se basa en la inacción, con lo cual no mejoraría su situación, cosa que no quiere, ya que, al igual que los criados y las rameras que aparecen en la obra, está preocupada por su bienestar económico. Concretamente, la medianera considera que acaparar dinero en el presente beneficiará su futuro:

Agora que voy sola, quiero mirar bien lo que Sempronio ha temido desde mi camino, porque aquellas cosas que bien son pensadas, aunque algunas veces hayan buen lìn, comúnmente crían desvariados efectos. Así que la mucha especulación sunca carece de buen fruto. (IV, 111)

Como meridianimente se advierte, a través de la cooperación, representada esquemáticamente en una matriz de resultados -o de pagos-, se pueden observar las opciones y bencticios que cada uno de los jugadores puede obtener como resultado del juego de suma no-cero: ${ }^{24}$

21 Se puede definir como un moxko de obtener una estrategia óptima para juegos que involucren a dos 0 más jugadores.

22 Véase Robert Gibbons. "Fiundaunentos y definición del equilibrio Nash," Un primer curso de teoriá de jue gos, trad. Paloma Calvo y Xivvier Vilà (Barcelona: Antoni Boscli. 2003) 8-15. Fundamental es también el trabajo de John Nash, "Equilibrium Points in N-Person Games." Proceedings of the National Academy of Sciences 36 (1950): 48-9, articulo fundacional de su célebre "equilibrio."

${ }^{23}$ Entendida como "ciada uno de los elementos que forman el espacio de decisión" (Cañas 268).

${ }^{24}$ En los juegos de suma no-cero la ganancia de un jugador no necesariamente se corresponde con la pérdida del otro. Además, los jugatuores pueden obtener los premios o pagos de forma simultánea, dado que el premio que cada jugador persigue es diferente en cadil cilso, por lo que, en este sentido, no existe un enfrentamiento ertre los beneficiados. En ambos casos calda jugador busca su máximo beneficio posible a través de la función de utilidall, que convierte los paros en bienestar.

\begin{tabular}{|c|c|c|c|}
\hline & \multicolumn{2}{|c|}{ CALISTO } \\
\hline & & COOPERA & NO COOPERA \\
\hline \multirow{2}{*}{ 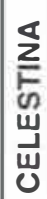 } & COOPERA & \$/ MELIBEA & $0 / 0$ \\
\hline & NO COOPERA & $0 / 0$ & $0 / \mathrm{MAL}$ DE AMOR \\
\hline
\end{tabular}

Para llevar a cabo su propósito la alcahueta se coloca en el centro de la ciudad, es decir, entre el mundo de los criados de Calisto y el de la alta burguesía a la que los dos amantes pertenecen. ${ }^{25}$ Este autoposicionamiento de la "remienda virgos" le proporciona ciertas ventajas sobre su contrincante. Concretamente, la vieja supera a Calisto porque es capaz de advertir una doble perspectiva del juego que se concreta. por una parte, en las intenciones de Calisto y, por otra, en los rechazos 'fingidos, 20 y devaneos de Melibea. Desde esta perspectiva que se despliega del terreno de juego, en estos dos espacios, Celestina, desde el centro, hace y deshace a su vera, ya que es capaz de entrar y salir de los espacios ajenos con suma facilidad. Celestina es, de esta forma, como en su día indicó Alcalá-Galán, un elemento extremadamente permeable y dinámico (4I)

Esta misma movilidad permite que Celestina vaya dos veces a la casa de Melibea. En su primera visita le refiere el "dolor de muelas" de su cliente. En la segunda provoca que Melibea identifique su sufrimiento al verbalizar el nombre del doliente Calisto

\section{Melibea: ¿Cómo se llama?}

Celestina: No te lo oso decir.

Mel.jBea: Di, no temas.

Celestina: Calisto (X, 227)

El pasaje evidencia cómo el lenguaje ayuda a materializar los deseos secretos de Melibea y, a su vez, aumenta el poder de la alcahueta sobre los dos jóvenes, pues "a quien dizes el secreto, das tu libertad" (II, 88). Así, la palabra y el control del discurso permiten que Celestina se adentre no sólo en el mundo de la alta burguesía a la que pertenece Melibea, sino también en su espacio interior. Si la vida de Melibea, en su calidad de amante, depende del discurso retórico de la alcahueta que termina delineando la figura de Calisto, la voluntad de la hija de Pleberio deberá cooperar con la voluntad de la alcahueta:

25 Se ha debatido muchisimo sobre las posiciones sociales de estos dos personajes, por lo que se les han considerado tanto miembros de la alta burguesía como conversos. Al respecto, Joseph T. Snow (2009), por ejemplo, ha afirmado que Pleberio es "al successful burgher" (135).

${ }^{26}$ Al respecto tengo preparado un artículo que he titulado "Melibea: el juego como estructura de identidad. 
Véole, scĩora, por una parte quejar el dolor, por otra temer la melecina. Tu temor me pone miedo, el miedo silencio, el silencio tregua entre tu llaga y mi melecina; así que será causa que ni tu dolor cese ni mi venida aproveche. $(X, 223)$

El silencio, entonces, es el elemento que muy posiblemente eliminaría a li medianera del juego. Por eso reconoce ante Melibea que sin la palabra jamás podrá sanar ni a la joven doncella ni a Calisto, pero, sobre todo, sin el valioso poder que le otorga la palabra, se quedaría sin premios o pagos. La palabra es, consecuentemente, lo que permite a la alcahueta tejer sutilmente las voluntades de los amantes y de otros participantes del juego, ${ }^{27}$ como muestril la voluntad de los criados para que, de este modo, sus planes funcionen a la perfección.

Asimismo, la dilación del tiempo de espera del intercambio sexual entre Melibea y Calisto contribuye a que la trotaconventos reaclive, periódicamente, el interés de los dos futuros amantes y acreciente el villor de su trabajo como medianera Celestina se aprovecha de la vulnerabilidad de los dos jóvenes para conseguir lo que ella más desea -riqueza y ser la mejor col sul oficio:

Una sola soy en este limpio trato; col Iodla la ciudad. pocos tengo descontentos, con todos cumplo los que algo me mandin!. (')Ino si toviese veinte pies y otras tantas manos. ( V, 131)

A partir de lo anterior se puede inferir yıc. ‘ll esic juego, Calisto está en clara desventaja, dado que únicamente cuenta coul su pusición social y con su dinero como recursos para jugar frente a Celestina. Comtrarimuk 'nle, la medianera tiene en su favor yarias habilidades, tales como engañar. conveilc's y lorcer los razonamientos, esto es, posee un gran poder embaucador a través de li pillihra. Para Celestina, consecuentemente, la palabra es el vehículo necesilti() gur i) ('ngitiar, como ha mencionado Julio Rodríguez Puértolas (154), puesto que la red liclic;i se explica, en parte, a partir de la manipulación del capital simbólico.

Dentro de la microciudad que Rojas Hencrenlis la acción de Celestina como medianera la pone en ventaja frente a sil cumlimlinlc: "A quien no me quiere no le busco, de mi casa me vienen a sacar, ("II III ('isil nle ruegan" (XII, 259). Por esta

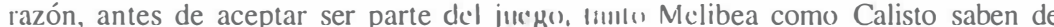
antemano la función de Celestina y cu fodk mumento son conscientes de las artimañas que la medianera emplea comminm!nutc ('I sus trabajos. De ahí que desde el inicio de la obra Melibea reconozcu:

No me maravillo, que un solo mmesiru de vicios dicen que basta para corromper un gran pueblo. Por cicrlu, lanlın y lille's loores me han dicho de tus falsas mañas que no sé si crea que perlias mminin. (IV, 131)

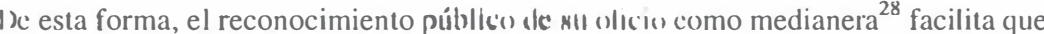
liı alcahueta penetre en la casa de Melilıei, ıuıc|uc sc:i bajo el engaño de "vender un poco de hilado," para así desplegar sul ،lincursu crrilico, que, según Sánchez, es el

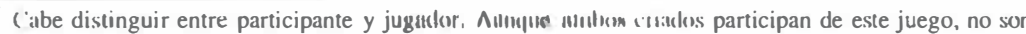

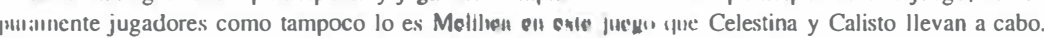

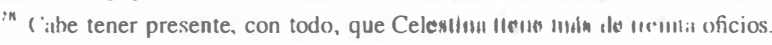

capital simbólico que pone en contacto la mercantilización con la esfera íntima de los hombres del inicio del Renacimiento (20).

Lo anterior posibilita explicar por qué tanto los diálogos entre Melibea y Celestina, así como los que se dan entre Calisto y Celestina, están marcados por un eminente tinte erótico. ${ }^{29} \mathrm{La}$ "vieja barbuda" recurre al discurso erótico para que, tanto la doncella como Calisto, imaginen representaciones sobre su objeto de deseo y, con esto, abandonen su voluntad a los deseos de la medianera. En cierto sentido, consecuentemente, la palabra de Celestina busca penetrar la esfera íntima de los enamorados para ejecutar una acción económica como evento simbólico (Bourdieu 19). ${ }^{30}$

Pero, iqué se esconde detrás de la figura de la medianera y su función social?; es decir, icuáles son las estrategias que desarrolla Celestina para que el mercantilismo penetre en el mundo íntimo? Para dar una respuesta convincente a estas preguntas es necesario entender que la realidad de Rojas se caracteriza por la insatisfacción económica por parte del servicio doméstico, del mundo de la prostitución y de la delincucincia. Aparte de la aristocracia urbana y del clero, la mayoría de la población, como es sabido, estaba totalmente insatisfecha e inconforme con la distribución de la riqueza y con la jerarquización de la sociedad.

En la ubril, por consiguiente, se puede distinguir cómo Celestina representa claramente el 'yo' egoísta que busca penetrar el mundo de la aristocracia urbana para obtencr, por medio de su palabra, riquezas. En efecto, son estos conflictos económicos los que configuran y constituyen las diferentes esferas de producción simbólica. yuc incluyen imágenes, conceptos y entendimientos prácticos de la vida diaria. De ahí (que Celestina, muy astutamente, establezca una empresa de carácter erótico-m)mclaria que sustenta en su supuesta 'amistad' con los criados, con Areúsa, con Elicia () con Melibea:

Sempronio: Madre bendita, ¡qué deseo traigo! Gracias a Dios que te me dejó ver.

CELI:SIINA: Hijo mío, rey mío, turbado me has; no te puedo hablar. Torna y dame otro abrazo. ¿,Y tres dias podiste estar sin vernos? $(I, 48)$

Así, los lazos de anmislad que establece la medianera con su nuevo 'amo' Calisto son vitales paril este juego:

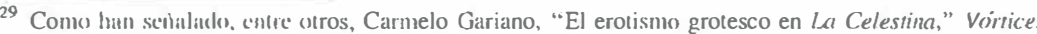
Literatura, Arre y ('viricu 1.3 (1975): 2-16; Eukene Lacarra Sanz, "Sobre los 'dichos lascivos y rientes'

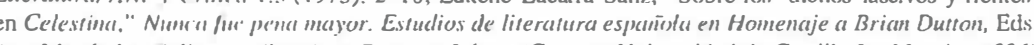
Ana Menénde, Cisllerit y Vicioriano Roncero López (Cuenca: Universidlad de Castilla-La Mancha, 1996) 419-33; y. Imis recicutencente. Louise O. Vasvári. "Escolios para el vocabulario de la Celestina: la seducción die ['inme'no," Hipertieira: Art \& Literature International Journal 3 (2002): n. p. En línea el 27 de abril cke 2(1)(k). hulp.//www.sinc.sunysb.edu/Publish/hiper/num3/artic/vasvari2.htm; véase, igualmente. Fernando (cintulanifedrat, "Risial. rcligiosidad y erotismo en La Celestina," El mundo social y cultural de

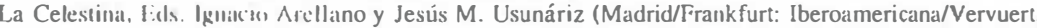
2003) $45-7(1)$

${ }^{30}$ Como ya mencionć con iunterioridad, algunos lectores pueden pensar en el hecho de que Celestina no hace nadia, il traturse de unia construccion autorial. Sin embargo. me inclino por tratarlo como ser humano, con vida propiu c e inclependencia, a pesar de los problemas teóricos que la crítica más tradicional pueda observer all resinecilo. 
Mira, inira, que está Celestina de tu parte, y que aunque todo te faltase lo que en un enamorado se requiere, te vendería por el más acabado galán del mundo, que te haría llanas las peñas para andar, que te haría las más crecidas aguas corrientes pasar sin mojarte. Mal conoces a quien das tu dinero. (XI, 235)

De acuerdo con lo anterior, las negociaciones de Celestina dependen de su capacidad para presentar, siguiendo ciertos códigos del amor cortés, a Calisto ante Melibea. Es decir, que 'disfraza' tanto el motivo erótico como a la negociación de dolor a través del empleo de un conjunto de imágenes y códigos culturales con los que están familiarizados los dos jóvenes.

El capital con el que se inicia la empresa de Celestina se reduce a un acervo o corpus de carácter simbólico que incluye la amistad y el sexo, esto es, aquellos "elementos propiamente ideacionales o culturales que aun estando dirigidos a la obtención de un beneficio económico desarrollan una lógica propia y autónoma en el nivel de los significados, exclusivamente" (Sánchez 23). La alcahueta, teniendo una perfecta visión del pasado, presente y futuro, reconoce la necesidad que impera en la sociedad de construir imágenes eróticas que provoquen que aquéllos que poseen bienes los distribuyan fuera de su círculo social. Celestina se encarga, entonces, de mediatizar la distribución de los bienes aunque, muchas veces, en ella es en donde termina esta fluctuación del bienestar.

Por ello, la sexualidad y su discurso son esenciales para que Celestina establezca lazos de amistad con las diferentes esferas de la sociedad, incluyendo al clero. En gran medida, ella contribuye a mantener cierta cohesión en la sociedad, puesto que, si por una parte, impide que los criados se vuelquen sobre las riquezas de sus amos, por la otra permite que la alta burguesía satisfaga sus deseos carnales y movilicen sus bienes. ${ }^{31}$ Sin embargo, al final de la Tragicomedia, y como consecuencia directa de la toma de consciencia del 'yo' egoísta de los criados, la medianera pierde su poder y control sobre ellos, lo que origina su muerte, como se verá.

De esta manera, la 'oferta' que Celestina hace al mundo del Renacimiento es la mezcla de la sexualidad con el dinero, pero sin ninguna valoración moral de por medio. Para la alcahueta, la sexualidad no pertenece a la intimidad de los amantes, sino a la actividad económica, a la esfera del intercambio. Así, los dos factores que pueden poner en riesgo su empresa son la moral y su avaricia, o, por el contrario, ¿Es el hecho de que la clase insatisfecha con su realidad, en este caso los criados, sean clientes y, a la vez, medianeros en este negocio sexual? En el caso de ser así, este doble posicionamiento de los criados les conduciría a tomar consciencia de que no son ellos quienes reciben los beneficios o ganancias de las transacciones en las que también colaboran. Consecuentemente, lo anterior, provocaría el incremento de la avaricia en estos jugadores.

Una vez penetrado el mundo del ocio y de la contemplación en que se encuentran Melibea y Calisto, la alcahueta obtiene, de sus dos visitas a casa de Melibea, sendos

\footnotetext{
${ }^{31}$ Es cierto, como ha demostrado Eukene Lacarra, que las alcahuetas no se consideraban agentes de la cohesión social: "la pena para las alcahuetas que corrompían a las mujeres honradas era con frecuencia muerte en la hoguera, al considerar este delito más grave, por realizarse por medio de la fuerza y del engaño, y subvertir la institución matrimonial, base sobre la que se asentaba el orden social y económico de los municipios" (35). Pero, ¿Es esta la visión que se ofrece en la obra?
}

premios gracias al retorcimiento de los razonamientos. Su deseo por los bienes materiales la lleva incluso a contradecirse, ${ }^{32}$ pues, con tal de que Melibea ceda ante su oferta, la alcahueta acepta que sería mejor para todos si ella mantuviera la lengua atada a la razón, lo cual se opone a su manera de ser en tanto que medianeraembaucadora:

Y pues conoces, señora, que el dolor turba, la turbación desmanda y altera la lengua, la cual había de estar siempre atada con el seso, por Dios que no me culpes. Y si él otro yerro ha hecho, no redunde en mi daño, pues no tengo otra culpa sino ser mensajera del culpado; no quiebre la soga por lo más delgado. (IV, 130)

Si Celestina, como Mercurio, continúa ejerciendo su función de "mensajera" obtendrá premios en forma de bienes materiales como, por ejemplo, las "cien monedas de oro" que consigue al final del primer auto, una vez sellado el pacto económico con Calisto. El hecho de que Celestina enfoque todos sus esfuerzos en la recompensa económica que le traerán sus acuerdos con el joven la hace ser un personaje mucho más 'libre,' sobre todo porque los demás no sólo desean el placer sino, también, la posesión o disfrute del cuerpo del otro. Por el contrario, Celestina no desea no sólo el placer sino el poder:

No les pena, no veen, no oyen, lo qual yo juzgo por otros que he conocido menos apasionados y metidos en este huego de amor que a Calisto veo [...]

Allí tienen los cuerpos; con sus amigas los corazones y sentidos. (IX, 209-10)

Si bien ello la pone, de entrada, en una clara posición de ventaja frente a los demás personajes, su avaricia le sitúa en el lugar totalmente opuesto. Su labor como mediadora la libera del dominio ajeno: no tiene deudas ni dependencias con nadie como podrían tener los criados hacia sus amos. Ella es una jugadora 'libre' que se mueve con gran facilidad y que, además, puede deshacer fácilmente los lazos con sus 'clientes,' a pesar de las dudas que manifiesta en la primera parte del auto IV:

Que, aunque yo he disimulado con él, podría ser que, si me sintiesen en estos pasos de parte de Melibea, que no pagase con pena que menor fuese que la vida; o que muy amenguada quedase, cuando matar no me quisiesen, manteándome o azotándome cruelmente. ¡Pues amargas cien monedas serían éstas! ¡Ay cuitada de mí, en qué lazo me he metido! Que por me mostrar solícita y esforzada pongo mi persona al tablero. (IV, 111)

"Ponerse en el tablero," a pesar de ser una frase hecha, muy bien se puede usar aquí como metáfora que alude directamente al juego y que habla por sí misma de las intenciones lúdicas en la obra de Rojas. A pesar de estos monólogos de carácter dubitativo y dado que la economía de la sociedad se basa en el comercio del sexo, Celestina continúa siendo el principal medio para distribuir este tipo de beneficios.

${ }^{32}$ Ello era de esperar, ya que Celestina suele contar mentiras $y$, por lo tanto, no le importa contradecirse si con ello obtiene el resultado que desea. 
Al considerar todas las ventajas de Celestina se puede decir que el cuadro situacional del juego ${ }^{33}$ es claramente favorable a la medianera, pues cada punto, o situación particular, le ha generado una combinación y número importante de premios. Es precisamente por este motivo que en el auto IV de la Tragicomedia aparecen mencionados, más y en mayor número de veces, diferentes tipos de dolor. Así, verbigracia, "doliente" (IV, 135), "apasionado" (IV, 132). Inclusive, Celestina hace mención al "dolor de muelas" (IV, 129), con clara alusión al deseo sexual:

Una oración, señora, que le dixeron que sabías de Santa Polonia para el dolor de las muelas. Assimesmo tu cordón, que es fama que ha tocado todas las reliquias que hay en Roma y Jerusalem. Aquel caballero que dixe, pena y muere dellas; ésta fue mi venida, pero pues en mi dicha estaba tu airada respuesta, padézcase él su dolor en pago de buscar tan desdichada mensajera. (IV, 111)

La abundancia de referencias al dolor es una muestra meridianamente clara de momento climático que el auto IV supone para la obra. Específicamente, indica la influencia del episodio en el desenlace de este juego, el cual se puede igualmente explicar a través de la teoría de juegos, puesto que ésta conduce, casi siempre, a determinar el resultado final de la solución de dicho juego. ${ }^{34}$ En el caso de la Tragicomedia será un resultado 'fatal del juego,' según la denominación que esta teoría ofrece.

Como se ha venido mencionando, el juego entre Calisto y Celestina es un juego de suma no-cero donde el final se podía predecir, a través de una intuición educada haciendo caso a las premoniciones que la propia alcahueta tuvo sobre su propia muerte en el auto IV, así como en otros momentos de la obra. Más concretamente Celestina, sabedora y orgullosa de sus poderes y facultades, augura tres veces su final trágico, aunque no es consciente que en la tercera estaba ya muy cerca su hora: "Que si me ha dado algo," dice Celestina a los criados, "dos vezes he puesto por él mi vida en el tablero" (IV, 111). Sin sospecharlo, la medianera está arriesgando su vida por tercera vez, la cual perderá ante la ira de los criados en el auto XII, para quienes "el dinero y los alimentos componen el único horizonte de abundancia que les es dado imaginar" (Ladero Quesada 221). Parece así que el final de la medianera es producto de la ironía trágica que Rojas hace funcionar en su obra, dado que son sus propias "amistades" las que acaban con ella, lo que no debe de extrañar si se considera que Celestina, movida por su extrema avaricia, rompe las reglas del juego, por lo que este se debe concluir.

Sin embargo, como se había hecho notar, antes de la traición de los criados, ya en el auto IV, Celestina había temido perder la vida en el intento de cumplir su misión o, cuando menos, preveía el riesgo de ser manteada y azotada cruelmente. Con todo, a pesar de sus más que fundadas dudas, la vieja decide continuar en el juego de la negociación del dolor, del poder y de las relaciones económicas porque, entre otras cosas, los agüeros, indicio de fortuna, le son favorables:

${ }^{33}$ Es decir, el conjunto total de situaciones posibles.

${ }^{34}$ Se entiende por solución en un "sentido similar al informal del resultado, o con el significado de conclusión del análisis de un problema" (Cañas 269).
Todos los agüeros se aderezan favorables, o yo no sé nada desta arte. Cuatro hombres que he topado, a los tres llaman Juanes y los dos son cornudos. La primera palabra que oí por la calle fue de achaque de amores; nunca he tropezado como otras veces; las piedras parece que se apartan y me hacen lugar que pase; ni me estorban las haldas, ni siento cansancio en andar; todos me saludan; ni perro me ha ladrado, ni ave negra he visto, tordo ni cuervo ni otras noturnas. Y lo mejor de todo es que veo a Lucrecia a la puerta de Melibea. Prima es de Elicia; no me será contraria. (IV, 113)

Celestina, a pesar de tener innumerables oficios, como el de vender hilo, podría haber optado por cualquier otra solución que le habría permitido sobre vivir en el sistema social del momento Sin embargo, por lo contrario, decide seguir jugando cobrar así su último pago, ahora en forma de una "cadenilla:"

¿Cadenilla la llama? ¿No lo oyes, Sempronio? No estima el gasto. Pues yo te certifico no diesse mi parte por medio marco de oro, por mal que la vieja la reparta. (XI, 233)

Alcanza así su principal objetivo. Sin embargo, aunque la vieja haya ganado el juego con Calisto, ha perdido la posibilidad de jugar más partidas. Su capacidad para construir el futuro de los amantes ha sido anulada por su avaricia como la de Pármeno y Sempronio. Con esto, los criados arrebatan el poder de penetración y movilización que anteriormente era privilegio de la 'trotaconventos.'

Por su parte, Calisto, una vez finalizada su negociación con la alcahueta, obtendrá su premio con la entrega sexual de Melibea (XIV). En cierto sentido, se puede decir que las palabras y estrategias de la mediadora continúan teniendo efecto aún después de su muerte. Es decir, que la penetración del mundo mercantilizado en la esfera íntima de los amantes ha sido, desde este punto de vista, todo un éxito. De esta forma, la muerte de Celestina no es más que el desequilibrio producido por la traición y engaño en el juego simultáneo que se desarrolla entre ella y los criados.

Se podría concluir, por tanto, sugiriendo que la teoría de juegos permite sacar a flote los mecanismos internos, esto es, la anatomía lúdica de Celestina, hasta ahora inadvertida por la crítica ${ }^{35}$ - ¿quién juega, con qué o con quién, para qué, con qué objetivo, cuáles son las reglas constitutivas, en qué consiste ganar?-, a la vez que precisar las insuficientes definiciones de lo que se puede entender como juego, de acuerdo con las definiciones tradicionales de éste - tal es el caso de Huizinga, Eugen Fink y Roger Caillois. ${ }^{36}$ A su vez, permite ensayar un nuevo método crítico no utilizado hasta el día de hoy en las letras medievales, del Renacimiento y Barroco hispánicos. Más concretamente, este tipo de aproximación interdisciplinar pone en tela de juicio la continua negación que se hace del interés material que reside en el estudio de la esfera lúdica (Huizinga 27).

${ }^{35}$ Con ello no me refiero a la idea la contienda, sino al juego.

36 Johan Huizinga, Homo ludens (Madrid: Alianza, 2000); Eugene Fink, Le jeu comme symbole du monde (Paris: Minuit, 1966); Roger Caillois, "Unity of Play: Diversity of Games," Diogenes 19 (1957): 92-121 y Les jeux et les hommes: le Masque er le Vertige (Paris: Gallimard, 1967) 
Ademais, esta lectura permite explicar el signiticado de lo lúdico, que se concreta en el intento de aprehender la realidad en un momento de profundos cambios para, así, ensayar las futuras relaciones sociales y económicas, a la vez que facilita la comprensión de la dinámica de las redes económicas de Celestina que se basan en los intercambios de carácter sexual y que afectan a las dos clases sociales-una aristocracia y la plebe de criados y rameras que depende económicamente de la medianera- que cohabitan en un "microcosmos urbano." Todo ello, organizado a partir de varios juegos - aunque aquí me he centrado en el que establece entre Celestina y Calisto-, en torno al eje del comercio sexual, y, que, como se ha visto, estuvieron perfectamente pensados y elaborados por el autorles de Celestina. De esta manera, la dimensión y dinámica lúdica de la obra se hace indispensable para la mejor comprensión del texto.

\section{Obras Citadas}

Alcalá-Galán, M. (1996). Voluntad de poder en Celestina. Celestinesca, 20(1-2), 37-55. Amasuno Sarraga, M. V. (2000a). Calisto, entre 'amor hereos' y una terapia falaz. Dicenda: Cuadernos de filologia hispánica, 18, 11-49.

Amasuno Sarraga, M. V. (2000b). Hacia un contexto médico para Celestina: Sobre "amor hereos. y su terapia". Celestinesca, 24(1-2), 135-169.

Baranda, C. (2004). La Celestina y el mundo como conflicto Salamanca: Ediciones Universidad de Salamanca.

Bourdieu, P. (1997). Razones prácticas. Sobre la teoria de la acción. Barcelona: Anagrama

Brams Steven, J. (1994). Game theory and literature. Games and Economic Behavior, 6.1, 32-54.

Caillois, R. (1957). Unity of play: Diversity of games. Diogenes, 19, 92-121.

Caillois, R. (1967). Les jeux et les hommes: le Masque et le Vertige. Paris: Gallimard.

Cañas, L. (2008). El falso dilema del prisionero. Una visión más amplia de las decisiones racionales. Madrid: Alianza.

Cantalapiedra, F. (2003). Risa, religiosidad y erotismo en La Celestina. In 1. Arellano \& J. M. Usunáriz (Eds.), El mundo social y cultural de LaCelestina (pp. 45-70). Madrid/Frankfurt: Iberoamericana/ Vervuert.

de Lucena, L. R. (1953). Repetición de amores e arte de axedrez: con CL juegos de partido (h. 1497). Madrid: Joyas.

de Miguel Martínez, E (1996). La Celestina de Rojas. Madrid: Gredos.

Deleuze, G., \& Guattari, F. (1980). Mille plateaux. Paris: Minuit.

Deyermond, A. (1977). Hilado-Cordón-Cadena: Symbolic equivalence in La Celestina. Celestinesca, 1.1, 6-12.

Deyermond, A. (1978). Symbolic equivalence in La Celestina: A postscript. Celestinesca, 2.I, 25-30. Deyermond, A. (1984). Divisiones socio-económicas, nexos sexuales: la sociedad de Celestina. Celestinesca, 8.2, 3-10.

Fink, E. (1966). Le jeu comme symbole du monde. Paris: Minuit.

Gadamer, H. G. (1997). Verdad y Méiodo. Salamanca: Sígueme.

Gadamer, H. G. (1998). La actualidad de lo bello. Barcelona: Paidós.

Gariano, C. (1975). El erotismo grotesco en La Celestina. Vórtice: Literatura, Arte y Crúica, 1.3, 2-16.

Gibbons, R. (2003). Un primer curso de teoria de juegos. Trads. Paloma Calvo y Xavier Vila. Barcelona: Antoni Bosch.

Gimeno Casalduero, J. (1992). La Celestina y su prólogo. In A. Vilanova (Ed.), Actas del X Congreso de la Asociación Intemacional de Hispanistas (Vol. 1, pp. 215-222). Barcelona: PPU.

Huizinga, J. (2000). Homo ludens. Madrid: Alianza.

Lacarra Sanz, E. (1993) La evolución de la prostitución en la Castilla del siglo XV y la mancebía de Salamanca entiempos de Fernando de Rojas. In I. A. Corfis \& J. T. Snow (Eds.), Fernando de Rojas and "Celestina:" Approaching the Fifth Centenary: Proceedings of An International Conference in
Cinumumurution of the 450th Amiversary of the Death of Fernando de Rojas (pp. 33-78). Madison: Ilispunic Scominary of Medieval Studies.

Lentina. In A. M. Collera \& V. R. Lópura en Homenaje a Brian Dutton (pp. 4(9)-4.33). Cuenca: Universidad de Castilla-La Mancha.

(pestellana de Celestina. In S. López Ríos (Ed), Estudios solre Celestina (pp. 213-240). Madrid: Istmo.

In S. López Ríos (Ed.), Estudios solre Celestima (pp. 2 'La Celestina'. Buenos Aires: Eudeba.

Lida de Malkiel, M. R. (1962). La originalidad artistica de La Celestina.." "Game and Theories of arino, J. A. G. (1985). "Annotated Bibliography or Play and Littérature Comparée 12

Game/Jeu et theories des jeux." Revute Camadienme de Limerarure Compedioevo? In Concepción

Martinez, E. J. R. (1993). La razón matemática del mundo ¿Una búsqueda del Medioevo? In Concepción Company, A. González et al. (Eds.), Voces d

Medievales) (pp. 83-91). México: UNAM. Morros, B. (Ed.). (1999) Morres, B. (Ed.). (199). La distón demin Espaiola 79.276, 94-150.

moderna. Boletin de la Real Academia Espaniola 79.276 , Proceedings of the National Academy of

Nitsh, J. F., Jr. (1950). Equin Sciences, $36,48-49$.

J. (1976) Lelestina la negación de la negación. Literatura, Historia Alineación (pp. 147-171). Barcelona: Labor.

Tragicomedia de Calisto y Melibea. In F. J. Wuhera, G. Serés, P. Díaz-Mas, I. R. Arzálluz, \& F. Rico (Eds.), Barcelona: Crítica.

Re Celestinesca, 2.I, 13-23.

. y én los medios electrónicos. Barcelona: Paidós.

y '’n los medios electronicos. Barcelonad y algunos personajes de Celestina. Torre de Papel, 4.3, Sinche\% $\%$. 71 .

Sér. liarcelona: Critica.

. Bulletin of Hispanic Studies, 86.1, 133-143.

(2009). Celestina's houses. Bulletin of Hispanie Sina la seducción de Pármeno. HiperFeira asviri. L. O. (2002). Escolios para el vocaburial 3: n. p. En línea el 27 de abril de 2009. <http:// Art de Literature International Journal 3: n. p. En linea
www

(2002) Birds of a feather: Predator and prey in Celestina. Celestinesca, 26.1-26.2, 5-27. 